\title{
Hipertermia maligna fulminante em paciente pediátrico submetido à cirurgia ambulatorial: relato de caso
}

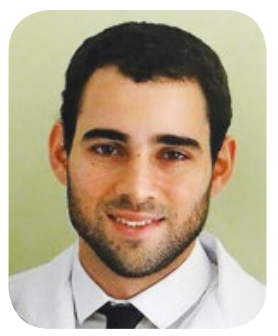

\author{
Luiz Alberto Bouzas Regueira', Ethyenne Lacerda Moreira ${ }^{1}$, \\ Catharina Borges de Oliveira ${ }^{1}$, Elton Pereira Sá Barreto Júnior ${ }^{1}$
}

\begin{abstract}
Palavras-chaves: hipertermia Maligna, Dantrolene, complicações intraoperatórias Key words: Malignant Hyperthermia, Dantrolene, Intraoperative Complications
\end{abstract}

\section{INTRODUÇÃO}

Hipertermia maligna (HM) é uma das mais devastadoras síndromes relacionadas à anestesia. Em indivíduos suscetíveis, a exposição a anestésicos halogenados e relaxante muscular despolarizante (succinilcolina) desencadeia elevação descontrolada dos níveis de cálcio intracelular das células musculares esqueléticas e consequente contração muscular contínua associada à hipermetabolismo. Caracteriza-se por elevação importante da temperatura, taquicardia, taquipneia, hipercarbia, rigidez muscular, acidose e hipercalemia. $\mathrm{O}$ tratamento consiste na interrupção imediata do agente gatilho e administração de dantrolene sódico intravenoso. Retardo no diagnóstico e no tratamento está associado à elevada mortalidade. Devido ao caráter hereditário e associação com síndromes genéticas, a história clínica torna-se importante na prevenção de sua ocorrência. ${ }^{1,2}$

\section{RELATO DE CASO}

LHLA, 12 anos, masculino, filho de pais divorciados, compareceu, acompanhado da genitora, à consulta pré-anestésica para cirurgia de herniorrafia inguinal esquerda associada à postectomia, correção de varicocele e exérese de cisto em epidídimo. Genitora negou comorbidades prévias ou história familiar conhecida de hipertermia maligna. Até então, não se sabia acerca dos dois óbitos ocorridos na família paterna, decorrentes de HM. Exame físico e exames pré-operatórios (hemograma, coagulograma, eletrocardiograma) sem alterações, sendo liberado para procedimento cirúrgico de nível ambulatorial.

Admitido na sala operatória e realizada monitorização multiparamétrica (cardioscopia, medidas intermitentes da pressão arterial não invasiva e oximetria de pulso). Puncionado acesso venoso periférico e induzida anestesia com fentanil $0,5 \mathrm{mcg} / \mathrm{Kg}$ e propofol $1 \%$ $2 \mathrm{mg} / \mathrm{Kg}$. Manutenção anestésica com sevoflurano via máscara facial, mantendo-se em ventilação espontânea, circuito aberto (sistema de Baraka) e monitorização contínua da capnografia. Procedida anestesia regional com Novabupiß $0,5 \%$ sem vasoconstrictor pelo cirurgião pediátrico. Paciente passou a cursar com taquicardia e hipercarbia. Feita suspeita de plano anestésico superficial, sendo complementadas dose de fentanil (total de $2 \mathrm{mcg} / \mathrm{Kg}$ ) e anestesia regional. Evoluiu então com contratura generalizada, sudorese profusa e hipertermia (temperatura $=39,5^{\circ}$ ). Nesse momento, feito o diagnóstico de hipertermia maligna com interrupção do anestésico halogenado, intubação orotraqueal, solicitação do dantrolene, resfriamento ativo e coleta de exames. Gasometria evidenciando acidose metabólica importante e hipercalemia. Procedida monitorização invasiva (pressão arterial, acesso venoso central, sondagem vesical) e passagem de cateter de hemodiálise. Administrados gluconato de cálcio, bicarbonato de sódio, iniciada solução polarizante e drogas vasoativas. Cursou, todavia, com parada cardiorrespiratória (PCR) em fibrilação ventricular com retorno à circulação espontânea (RCE) após desfibrilação e manobra de ressuscitação cardiopulmonar (RCP). Iniciada administração de dantrolene ( 3 bolus de $2,5 \mathrm{mg} / \mathrm{kg}$ e infusão contínua de $1 \mathrm{mg} / \mathrm{Kg} / \mathrm{h}$ ). Apresentou novos episódios de PCR (total de 06) em atividade elétrica sem pulso (AESP) com RCE após RCP e medidas para hipercalemia. Encaminhado para a Unidade de Terapia Intensiva (UTI) após melhor controle hemodinâmico. A despeito de todas as medidas, evoluiu com piora hemodinâmica progressiva, cursando com assistolia e óbito horas após admissão na UTI.

\section{DISCUSSÃO}

A Hipertermia Maligna é uma doença farmacogenética, de herança autossômica dominante, caracterizada por reação hipermetabólica após exposição a 
agentes desencadeantes (anestésicos halogenados e succinilcolina). As crises típicas apresentam quadro bastante semelhante ao paciente previamente relatado (taquicardia, hipercarbia, hipertermia, rigidez muscular, acidose metabólica e hipercalemia). Porém, devido principalmente à penetrância genética variável da síndrome, pode manifestar-se de formas atípicas, frustras, como espasmo de masseter isolado, até sua forma fulminante. Sua incidência varia de 1:50000 anestesias em adultos a 1:15000 em crianças, sendo o gênero masculino aparentemente mais afetado., ${ }^{3,4}$

Aproximadamente $50 \%-80 \%$ dos casos são relacionados a mutações no gene do receptor de rianodina tipo 1 e, em uma minoria, a mutações no canal de cálcio di-hidropiridínico. Ambos são responsáveis pelo controle dos níveis intracelulares de cálcio nas células musculares esqueléticas. Nos indivíduos predispostos, exposição a agentes desencadeantes provoca aumento excessivo dos níveis intracelulares, com consequente estímulo à contração muscular persistente, hipermetabolismo e rabdomiólise (Fig 1). ${ }^{1}$

Feita suspeita diagnóstica de HM, recomenda-se a interrupção imediata dos agentes anestésicos, hiperventilação com $\mathrm{O}_{2}$ a $100 \%$ em alto fluxo (10l/min), correção da acidose metabólica com bicarbonato de sódio $(1-4 \mathrm{mEq} / \mathrm{Kg})$, resfriamento ativo até $38^{\circ} \mathrm{C}$, monitorização do débito urinário e, se necessário, uso de diuréticos, correção de hipercalemia, além da administração precoce de dantrolene. Observação na UTI por, pelo menos, $24 \mathrm{~h}$ é recomendada mesmo após controle adequado dos sintomas. ${ }^{4}$

O dantrolene, um derivado hidantoínico, é a única medicação efetiva em reverter os sintomas de HM. Essa propriedade do dantrolene está possivelmente relacionada à sua capacidade em inibir o efluxo de cálcio do retículo sarcoplasmático das células musculares esqueléticas. Recomenda-se a administração de bolus de $2,5 \mathrm{mg} / \mathrm{Kg}$ (total de $10 \mathrm{mg} / \mathrm{Kg}$ ) a cada 5 a 10 minutos até controle dos sintomas. Sua administração precoce está relacionada à redução da morbimortalidade. A Resolução do Conselho Federal de Medicina (CFM 1802/2006) inclui o dantrolene na lista de fármacos obrigatoriamente disponíveis em instituições onde qualquer anestesia é realizada. Recomenda-se a disponibilidade imediata de trinta e seis frascos da medicação (frasco contendo 20mg), correspondente à dose para adulto de $70 \mathrm{~kg}^{3}$

Diante da gravidade do quadro clínico, prevenção é a melhor estratégia para a abordagem da HM. Adequada história clínica e identificação dos indivíduos suscetíveis são essenciais para planejamento anestésico apropriado. No caso específico relatado, o agravante do desconhecimento da genitora da história paterna de HM num contexto de divórcio litigioso impossibilitou a identificação e diagnóstico de susceptibilidade. O diagnóstico de susceptibilidade é feito através do teste de contração ao Halotano e à cafeína em material obtido por biópsia muscular em centros especializados. ${ }^{1}$

Pacientes suscetíveis podem ser anestesiados com segurança, inclusive em nível ambulatorial, desde que adequado preparo anestésico seja realizado. Técnicas de anestesia regional são preferíveis, porém, na impossibilidade para realização das mesmas, recomenda-se o uso de anestésicos "seguros" (exceto halogenados e succinilcolina) após preparo do apareIho de anestesia. O preparo do aparelho de anestesia é feito com a retirada dos vaporizadores, troca da cal sodada, passagem de fluxo de oxigênio contínuo com dez litros por minuto durante 10 minutos, instalação de novo circuito e troca da bolsa de ventilação. ${ }^{1,4}$

Infelizmente, nem sempre as crises de HM podem ser evitadas. Detecção precoce, administração imediata de dantrolene e presença de equipe multidisciplinar adequadamente treinada para assistência ao paciente são fundamentais para a obtenção de meIhores resultados.

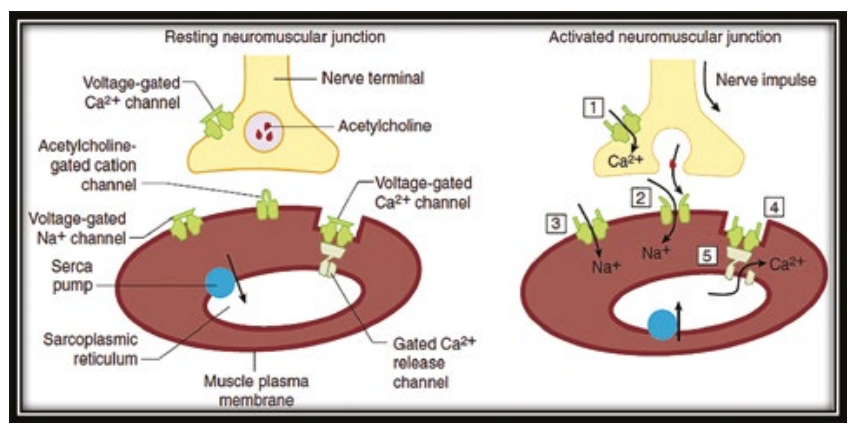

Figura 1 - Canais de cálcio envolvidos na transmissão neuromuscular e acoplamento excitação-contração. Fonte: MILLER, 2009, p. 1183

\section{REFERÊNCIAS}

1 - Zhou J, Bose D, Allen PD et al. Malignant Hyperthermia and Muscle-Related Disorders. In: Miller RD, Cohen NH, Eriksson LI et al. Miller's Anesthesia. 8 ed. Philadelphia, Elsevier, 2015; 1287-1314.e8.

2 - Dierdorf SF, Walton JS, Stasic AF. Rare Coexisting Diseases. In: Barash PG, Cullen BF, Stoelting RK et al. Clinical Anesthesia. 7 ed. Philadelphia, Lippincott Willimas \& Wilkins, 2013; 622-624.

3- Da Silva HCA, Almeida CS, Brandão JCM et al. 
Hipertermia Maligna no Brasil: Análise da Atividade do Hotline em 2009. Rev. Bras. Anestesiol. 2013; 63 (1): 13-26.

4 - Amaral JLG, Carvalho RB, Cunha LBP et al. Hipertermia Maligna. Projeto Diretrizes. Associação Médica Brasileira e Conselho Federal de Medicina. 2009.

1- Serviço de Anestesiologia do HSI

Endereço para correspondência:

luizalberto_b@hotmail.com 